\title{
Evolutional aspects of children and adolescents with surgically corrected aortic coarctation: Clinical, echocardiographic, and magnetic resonance image analysis of $\mathbf{1 1 3}$ patients
}

\author{
Margarida Maria da Costa Smith Maia, MD, PhDa \\ Tamara Martins Cortês, $\mathrm{MD}, \mathrm{PhD}^{\mathrm{b}}$ \\ José Rodrigues Parga, MD, $\mathrm{PhD}^{\mathrm{b}}$ \\ Luiz Francisco Rodrigues de Ávila, MD, PhD ${ }^{b}$ \\ Vera Demarchi Aiello, MD, PhD ${ }^{\text {b }}$ \\ Miguel Barbero-Marcial, MD, $\mathrm{PhD}^{\mathrm{b}}$ \\ Munir Ebaid, MD, $\mathrm{PhD}^{\mathrm{b}}$
}

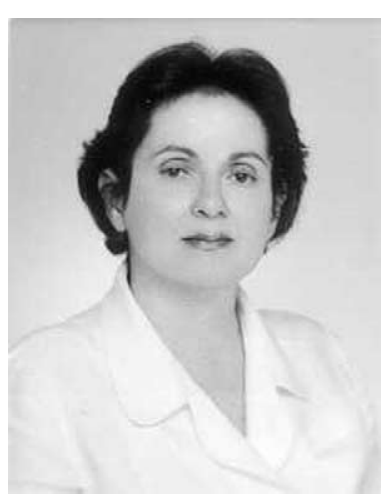

Dr Smith Maia

From the Faculty of Medicine ${ }^{\mathrm{a}}$ from Federal University of Minas Gerais, Department of Internal Medicine, Belo Horizonte, Minas Gerais, and Heart Institute (InCor), ${ }^{\text {b }}$ University of São Paulo Medical School, São Paulo, Brazil.

Supported by the Heart Institute (InCor), University of São Paulo Medical School, Brazil. Dr Smith Maia obtained a doctor's scholarship for 2 years from "CAPES" (Coordenadoria de Aperfeiçoamento de Pessoal de Nível Superior).

Received for publication March 13, 2003; revisions requested April 8, 2003; revisions received May 12, 2003; accepted for publication June 25, 2003.

Address for reprints: Margarida M. C. Smith Maia, Faculdade de Medicina da UFMG/Departamento de Clínica Médica, Av Alfredo Balena 190/4070, CEP: 30130100 Belo Horizonte, Minas Gerais, Brazil (E-mail: margamaia@bol.com.br).

J Thorac Cardiovasc Surg 2004;127:712-20

$0022-5223 / \$ 30.00$

Copyright (C) 2004 by The American Association for Thoracic Surgery

doi:10.1016/S0022-5223(03)01018-3
Objective: The goals of this study were to determine the prevalence of hypertension and recoarctation in operated children and teenagers and to integrate clinical and imaging technique data.

Methods: One hundred thirteen infants and children (ages 14 years or less) were retrospectively divided into 3 groups according to the age at operation and the surgical technique: 79 underwent resection with end-to-end anastomosis; 14 had patch enlargement; 13 had subclavian flap aortoplasty; and 7 had other techniques performed. The mean age at operation was $3.95 \pm 4.17$ years and the mean follow-up period was $4.62 \pm 4.90$ years. Each patient was clinically examined and Doppler echocardiography was performed in 112 patients. Sixty-six patients underwent magnetic resonance imaging. Diameters of aortic arch were measured at 4 levels; the ratios between each one and descendent aorta diameters were calculated. Qualitative variables and associations were studied by Fisher exact test or chisquared test. Comparisons of measurements in different groups were performed using variance analysis, with tests of selective contrasts (nonparametric tests). The level of statistical significance was $<.05$.

Results: The prevalence of hypertension and recoarctation was $38 \%$ and $14 \%$, respectively. No statistical difference was found among the age groups. In 65 patients who underwent magnetic resonance imaging, the transverse aortic arch was hypoplastic in $31(47 \%)$ patients; $41(63 \%)$ had stenosis at the site of anastomosis $($ ratio $<0.9)$.

Conclusion: Hypoplasia of transverse aortic arch was highly prevalent. These data suggest that hypoplastic aortic arch should be corrected concomitantly with coarctation.

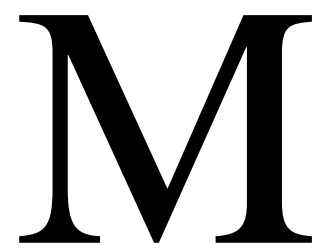

any follow-up studies of patients operated for aortic coarctation have shown a variable prevalence of recoarctation and systemic hypertension. The younger the child at the time of repair (particularly below 6 months), the higher the risk of recoarctation and the lower the risk of hypertension. ${ }^{1,2}$ When older children are operated for aortic coarctation, the late follow-up is poor with shorter survival due to cardiovascular complications and a great prevalence of systemic hypertension (20-68\%) when compared with the general population. ${ }^{3,4}$ Other aspects such as the surgical technique used, the criteria of aortic recoarctation, the morphological aspects of the lesion, and the postoperative follow-up are also important. 
There is no doubt that the surgical correction of aortic coarctation prolongs life. In 2 large follow-up studies, ${ }^{3,5}$ the authors emphasize the importance of using more sensitive image methods such as Doppler echocardiography and nuclear magnetic resonance in the study of recurrent coarctation. However, there are few postoperative follow-up studies that used imaging methods to obtain a greater sensitivity in the analysis of late complications. ${ }^{2,6}$

Our objective was to study children and adolescents (operated from birth to 14 years of age) to analyze (1) the prevalence of recurrent coarctation; (2) the prevalence of systemic hypertension; and (3) the correlation of imaging method findings and clinical data. To reach these objectives a detailed clinical observation was performed, as well as Doppler echocardiography and magnetic resonance imaging (MRI).

\section{Patients and Methods}

We studied retrospectively 113 patients operated for aortic coarctation at the Heart Institute (InCor), University of São Paulo, between 1970 and 1996. All individuals who had surgical correction of isthmic aortic coarctation up to the age of 14 years at our institution were called to take part in the study, except those with cyanotic heart defects. The final group corresponds to those who attended the solicitation and those being followed with regularly scheduled medical visits. They were divided into 3 groups, according to the age at the first operation, as follows: 0 to 1 year of age, 43 patients; 1 to 10 years, 53 patients; and older than 10 years, 17 patients. Surgical techniques were as follows: 79 had resection with end-to-end anastomosis; 14 had patch enlargement; 13 had subclavian flap aortoplasty; 4 had end-to-end anastomosis plus a flap of the left subclavian artery; 2 had Mendonças technique; 1 had end-lateral anastomosis of the subclavian artery. There was a prevalence of male patients $(n=76,67 \%)$ over females. The mean age at operation was $3.95 \pm 4.17$ years (age range: 11 days to 14 years; median: 2.35 years). The weight at the time of the first operation could be retrieved from the medical records in 109 patients; the mean value was $14.24 \pm 11.58 \mathrm{~kg}$ (range: $2.37-45.60$; median: 10.30). The mean follow-up period was $4.62 \pm 4.49$ years (range: 68 days and 26 years, 6 months; median: 3.32 years).

The clinical data, results from complementary preoperative exams, and information about anatomical aspects and operative techniques were obtained by reviewing recorded data and descriptions of surgery. In the postoperative period, all patients were called to a medical interview and physical examination, including blood pressure measurements taken on right and left arms and legs. The research was explained to the patients and consent was obtained from each participant or their parents. The ethics committee of the Heart Institute approved the study protocol. Blood pressure was sequentially measured by the aneroid sphygmomanometer and cuffs of 2.5, 5.0, 7.5, and $12.0 \mathrm{~cm}$. Patients were considered hypertensive when the mean of 2 measures of systolic and/or diastolic blood pressure on right arm was equal to or higher than 95th percentile for age as defined by the Task Force on Blood Pressure Control in Children ${ }^{7}$ or when they were prescribed antihypertensive drugs. For patients over 18 years of age, hypertension was considered when mean systolic and/or diastolic blood pressure was higher than 140/90 mm Hg. Distribution of blood pressure values and hypertension were studied according to age at operation. In 10 patients we were not able to obtain right arm blood pressure during first clinical exam, and blood pressure was obtained in 4 extremities in only $51(45 \%)$.

Recoarctation or recurrent coarctation was defined when the systolic gradient between the right arm and leg, measured with sphygmomanometer, was equal to or higher than $20 \mathrm{~mm} \mathrm{Hg}$. The same gradient was considered for Doppler echocardiographic measurements of aortic isthmus and descendent aorta. The right armleg gradient measured during clinical examination was considered the gold standard. The prevalence of recoarctation according to age groups was studied. Bidimensional echocardiography with continuous color Doppler and M mode was performed in 112 patients (1 patient could not be examined by this method due severe thoracic deformity). An Aloka SSD-80 machine (Aloka Co Ltd, Tokyo, Japan), with transducers of 3.5 and $5.0 \mathrm{mHz}$, was used to perform the exams. The slices were done as routine echocardiograms in congenital heart diseases. The systolic gradient in the aorta was determined by continuous map color Doppler in the isthmus or in descending aorta. Doppler gradient was calculated through simplified Bernoulli equation.

MRI was performed in 66 patients; the other $42 \%$ were not submitted to this examination because they were too young and parents did not permit general anesthesia. Gyroscan ACS 0.5T (Philips Medical Systems, Best, The Netherlands) and Signa LX CVI 1.5T (General Electric Co, Medical Systems Group, Milwaukee, Wis) scanner machines were used to perform the exams. The spin-echo images were obtained with sections of $3.0-$ and $5.0-\mathrm{mm}$ thickness in axial, sagittal, and coronal views. Aortic arch diameters were measured at 4 predetermined points, in 2 different views and maximal internal diameter. They were normalized by the aortic diameter at diaphragmatic level. ${ }^{8}$ Ascending aorta was measured in the anterior-posterior position in axial section, just above the aortic valve. The sagittal section aorta was measured at the following points: between brachiocephalic artery and left common carotid artery; between left common carotid and left subclavian artery; at isthmus and diaphragmatic level. In 1 patient with persistent fifth aortic arch not all measurements could be performed. Each normalized segment was studied for mean value and range according to the age at operation. Segment ratios smaller than 0.9 were considered hypoplastic according to Clarkson and Brandt. ${ }^{8}$ Those greater than 1.5 were assumed to be dilated. Recoarctation was considered when the ratio was smaller than 0.6 at the site of correction. ${ }^{2,9}$ Catheterization was performed in 11 patients when there was discrepancy among clinical and imaging data, heart failure, or indication to reoperation or balloon dilatation.

Qualitative variables and the possible associations were studied by Fisher exact test or chi-square test. For quantitative variables means, standard deviation, and minimum and maximum values were calculated. Comparison of measurements in different groups was performed using nonparametric test (Kruskal-Wallis), variance analysis to repeated measures (Friedman's test), test of selective contrast (Wilcoxon signed-rank test). The systolic gradient of blood pressure, Doppler gradient at echo, and MRI measurements were studied as a whole by determining Pearson's linear correlation coefficient. The level of statistical significance was 


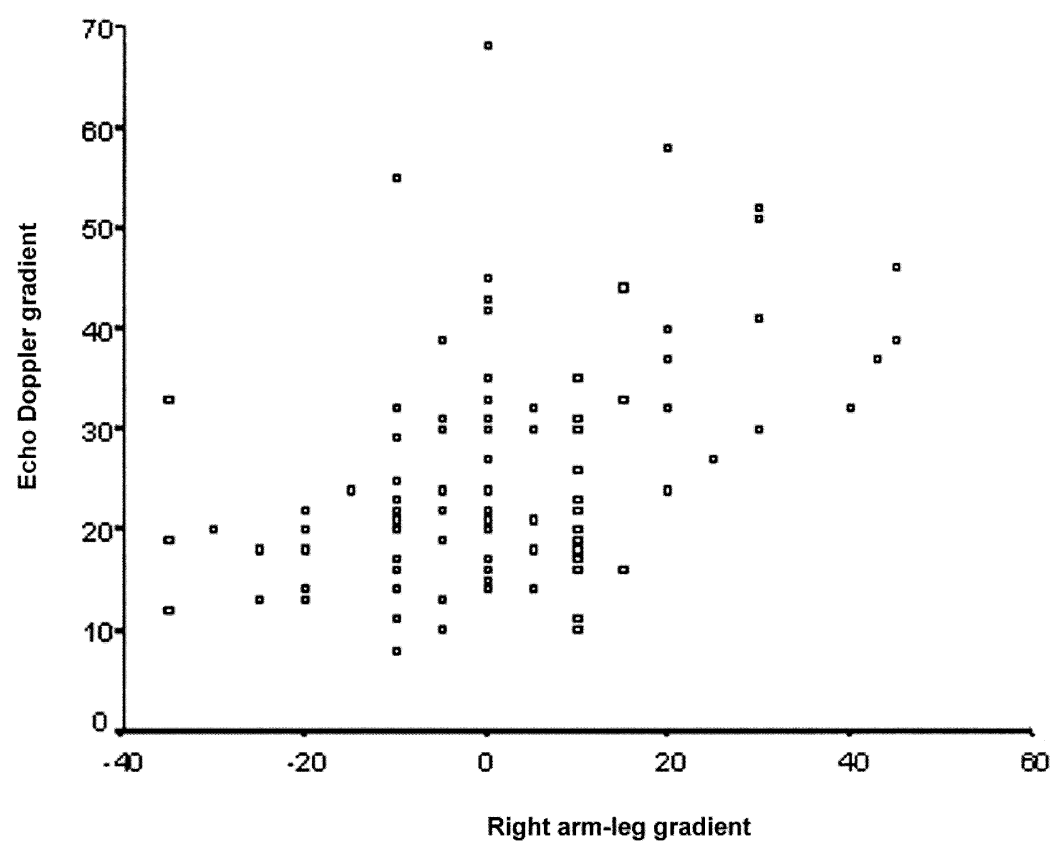

Figure 1. The instantaneous continuous peak Doppler gradient is plotted against right arm-leg systolic blood pressure gradient, obtained with sphygmomanometer, in 102 patients (Pearson correlation coefficient $r=.43, P=$ $.000)$.

$<.05$. Calculations were performed with the SAS system (Statistical Analysis System) and SPSS (Statistical Package for Social Science).

\section{Results}

\section{Associated Intracardiac and Extracardiac Anomalies}

Aortic coarctation was associated with other intracardiac anomalies in 89 patients (79\%) and isolated in 24 patients. Bicuspid aortic valve was the most frequent intracardiac defect $(48 \%)$. There was no significant difference in the distribution of this defect among the age groups (chisquared test). Patent ductus arteriosus was found in 39 patients (35\%); in 1 child it was not clear if ductus was patent. There was a statistically significant difference in the distribution of this defect among the age groups: it was more frequent below 1 year of age (chi-squared test, $P<$ .001). Other intracardiac-associated defects showed no significant difference in the distribution of age groups. Hypoplastic isthmus was a subjective observation during surgery in 21 patients; 2 patients had extreme coarctation and 9 patients had hypoplastic transverse aortic arch.

\section{General Clinical Aspects}

Of the 113 patients, 95 (84\%) were classified postoperatively as New York Heart Association (NYHA) functional class I and 18 as class II. Patient distribution in class II according to age groups was as follows: 0 to 1 year, 6 patients (14\%); 1 to 10 years, 5 patients (9\%); >10 years, 7 patients $(41 \%)$. There was a statistically significant difference in functional class II distribution among age groups, and this difference predominated in patients older than 10 years $(P=.007$, Fisher exact test).

Correlation analysis. The Doppler peak gradient obtained in 51 patients during echocardiographic exam was correlated with the following clinical variables:

1. Right arm-leg systolic blood pressure gradient (Pearson correlation coefficient and significance: $r=.44 ; P$ $=.0014)$. The Doppler peak gradient was estimated relative to the right arm-leg systolic blood pressure gradient $(20 \mathrm{~mm} \mathrm{Hg})$ and measured $30.9 \mathrm{~mm} \mathrm{Hg}$.

2. Left arm-leg systolic blood pressure gradient correlation coefficient was $r=.27(P=.06)$. There was no correlation between right or left arm-leg diastolic gradient. The right arm-leg systolic gradient and Doppler gradient correlation in 102 patients is shown in Figure 1.

Arterial hypertension. Before aortic coarctation operation, 86 of 101 patients $(85 \%)$ had hypertension. The distribution of patients with elevated blood pressure relative to age groups was not statistically significant (Fisher exact test). After the coarctation operation, 39 of 102 patients (38\%) had elevated blood pressure. Among these patients, 9 had recoarctation on clinical examination. There was no statistically significant difference in the distribution of pa- 


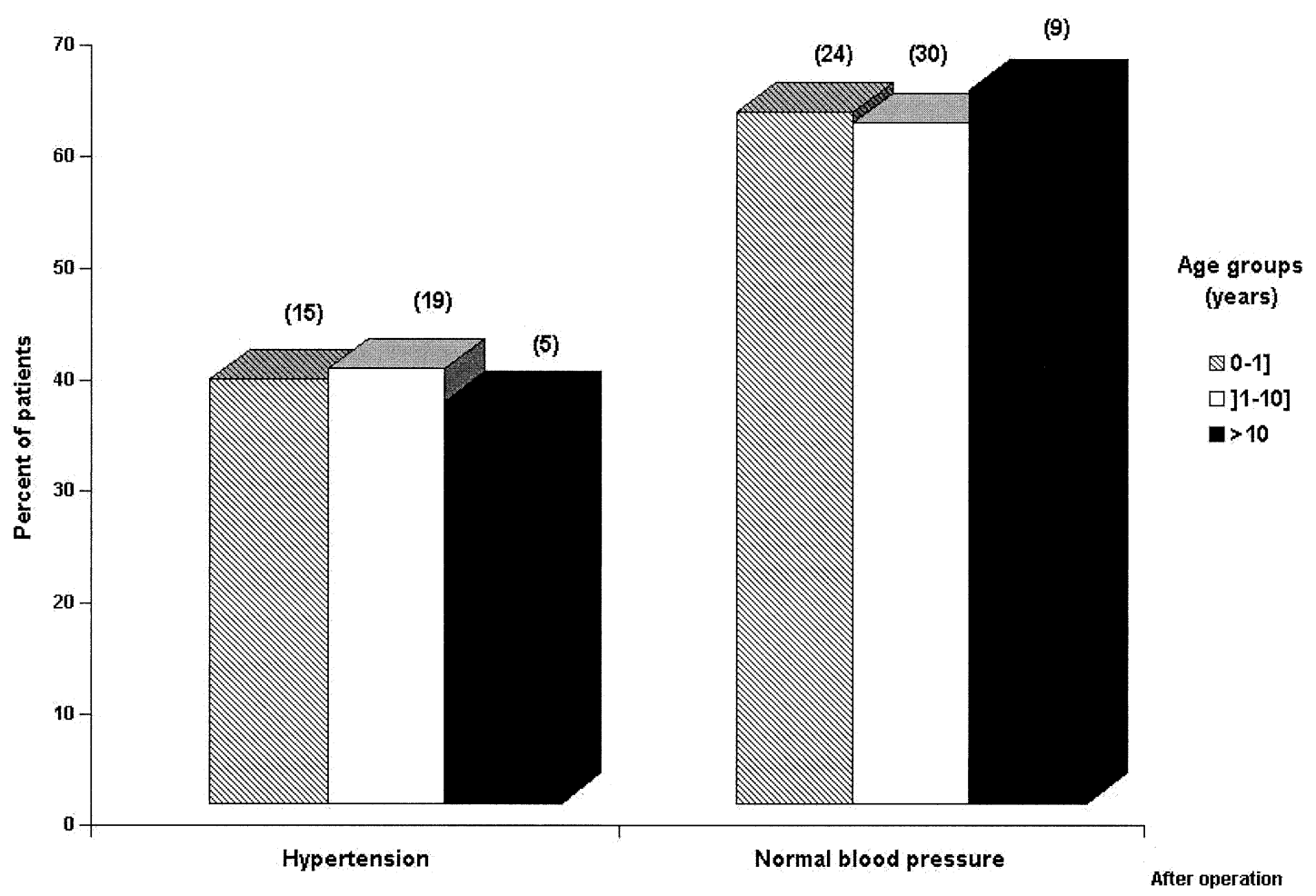

Figure 2. After operation 102 patients with high and normal blood pressure were distributed among age groups. The figures in parentheses refer to the number of patients in each age group.

tients with high blood pressure between age groups by Fisher exact test (Figure 2).

Recoarctation. Fourteen of 103 patients (14\%) had clinical evidence of recoarctation. There was a statistically significant difference in the distribution of patients with recoarctation according to age groups; it predominated in patients older than 10 years $(P=.014$, Fisher exact test $)$ (Figure 3).

These 14 patients were distributed according to operative technique as follow: (1) end-to-end anastomosis in 10 (14\%); (2) patch aortoplasty in 1 (7\%); (3) subclavian flap in $1(9 \%)$; (4) end-to-end anastomosis associated with subclavian flap in none; (5) Mendonças technique in 1; (6) end-lateral anastomosis in 1.

Considering the same gradient $(\geq 20 \mathrm{~mm} \mathrm{Hg}$ ) measured by Doppler, the quantity of patients considered as having recoarctation was higher, 73 of 112 (65\%). In 102 individuals the right arm-leg gradient was analyzed relatively to Doppler gradient. All 14 patients with clinical evidence of aortic recoarctation had Doppler gradient $\geq 20 \mathrm{~mm} \mathrm{Hg}$. On the other hand, in 88 patients with clinical right arm-leg gradient $<20 \mathrm{~mm} \mathrm{Hg}$, only 34 (39\%) had Doppler gradient $<20 \mathrm{~mm} \mathrm{Hg}$. Thus, gradient evaluation by Doppler showed great sensitivity $(100 \%)$ and low specificity $(39 \%)$ relative to the right arm-leg gradient.
Sixty-six patients were studied by MRI and $6(9 \%)$ had a ratio (aortic isthmus/aorta at diaphragm) $\leq 0.60$. The right arm-leg gradient in 64 patients was studied in relation to this ratio obtained by MRI (in 1 patient the right arm-leg gradient was missing and in another the isthmus measure could not be obtained). Six patients had this rate $\leq 0.60 ; 3$ of them had clinical evidence of recoarctation. Thus, the sensitivity of right arm-leg gradient was 50\% relative to MRI. In 58 patients with a ratio (aortic isthmus/aorta at diaphragm) $>0.60,49$ had no clinical evidence of recoarctation; specificity relative to MRI was $84 \%$.

Study of the aortic arch by MRI. The study of the aortic ratios, normalized by the aortic diameter at diaphragmatic level in 65 patients and divided according to age groups at operation, gave the results shown in Table 1 .

The aortic ratio median behaved the same way independently of the age at coarctation correction. There was no significant difference between the median ratios of each aortic level within all age groups (Kruskal-Wallis test). There was a statistically significant difference among medians of each aortic arch segment ratios in different age groups $(P=.000$, Friedman test). The median ratios along the aortic arch were progressively and significantly smaller from the ascending aorta to the isthmus in all age groups ( $P$ $=.000$, Wilcoxon signed-rank test) (Table 1). 
(31)

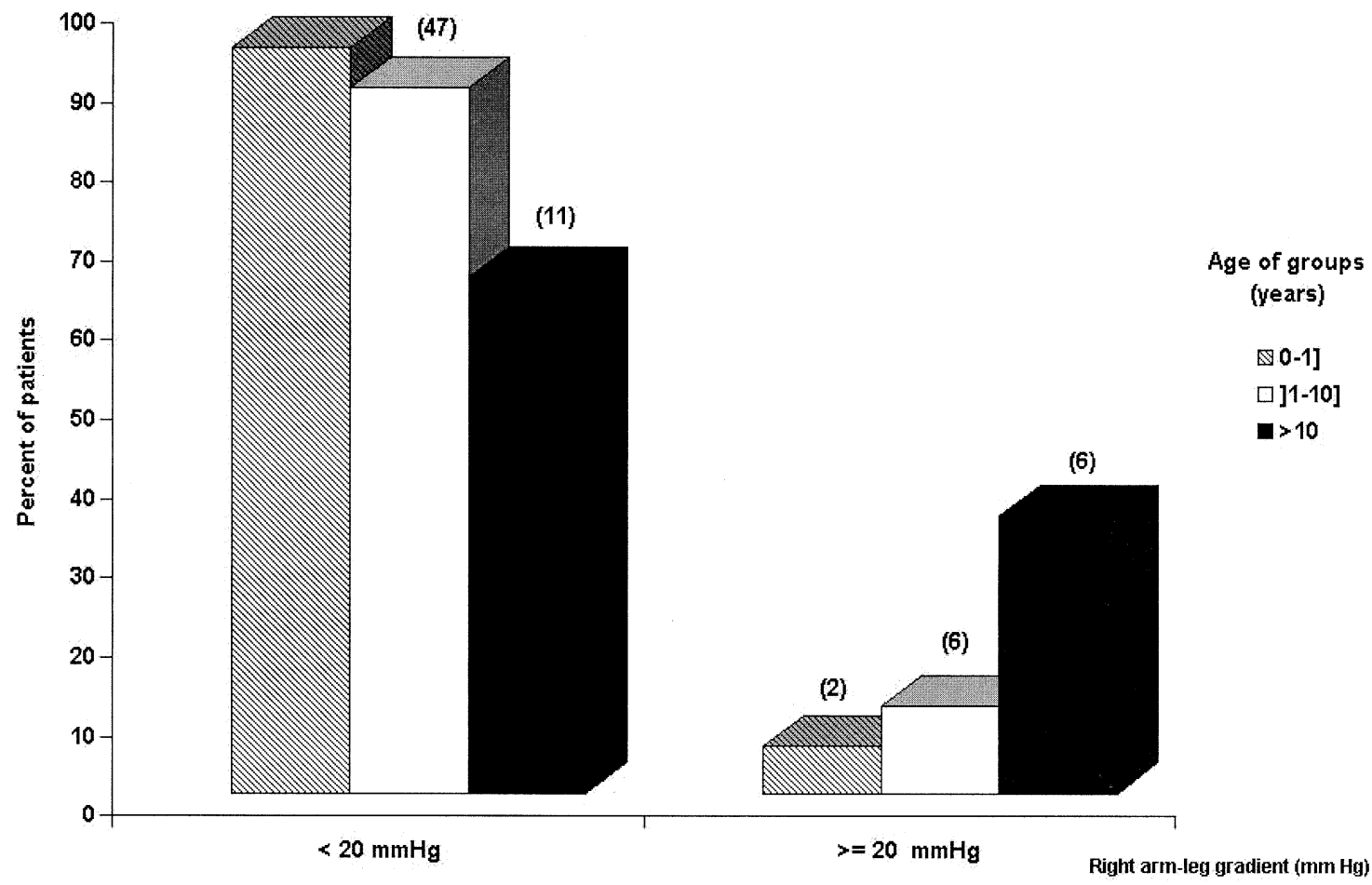

Figure 3. Patients were distributed among age groups according to right arm-leg systolic gradient. The numbers of patient are in parentheses.

TABLE 1. Range of the normalized aortic arch diameters with the aorta at diaphragmatic level

\begin{tabular}{llcccccc}
\hline $\begin{array}{l}\text { Age } \\
\text { groups } \\
\text { (years) }\end{array}$ & $\begin{array}{c}\text { Aortic } \\
\text { diameter } \\
\text { ratios }\end{array}$ & $\mathbf{n}$ & Mean & $\begin{array}{c}\text { Standard } \\
\text { deviation }\end{array}$ & Median & Minimum & Maximum \\
\hline $0-1$ & Asc-ao & 14 & 1.67 & 0.43 & 1.56 & 1.15 & 2.50 \\
& Bca-Icc & 14 & 1.09 & 0.23 & 1.07 & 0.71 & 1.42 \\
& Lcc-Isa & 14 & 0.89 & 0.15 & 0.94 & 0.63 & 1.10 \\
& Isthmus & 14 & 0.79 & 0.20 & 0.74 & 0.43 & 1.13 \\
$1-10$ & Asc-ao & 34 & 1.76 & 0.44 & 1.71 & 1.13 & 3.43 \\
& Bca-Icc & 34 & 1.08 & 0.19 & 1.00 & 0.71 & 1.43 \\
& Lcc-Isa & 34 & 0.93 & 0.20 & 0.93 & 0.45 & 1.40 \\
& Isthmus & 34 & 0.88 & 0.31 & 0.81 & 0.40 & 2.41 \\
$>10$ & Asc-ao & 17 & 1.63 & 0.27 & 1.60 & 1.25 & 2.33 \\
& Bca-Icc & 17 & 1.01 & 0.19 & 1.00 & 0.73 & 1.38 \\
& Lcc-Isa & 17 & 0.91 & 0.15 & 0.89 & 0.67 & 1.08 \\
& Isthmus & 17 & 0.88 & 0.26 & 0.83 & 0.55 & 1.67 \\
\hline
\end{tabular}

Asc-ao, Normalized ascending aorta with the aorta at diaphragmatic level; $B c a-I c c$, normalized proximal transverse aortic arch; Lcc-Isa, normalized distal transverse aortic arch; Isthmus, normalized isthmus.

The dimensions of the aorta at the site of correction were studied in 65 patients. In 41 (63\%) the isthmus/diaphragm ratio was smaller than 0.9 with some degree of stenosis. In $22(34 \%)$ it was between 1.0 and 1.4 and considered normal. In $2(3 \%)$ it was larger than 1.5 and considered as aneurys- matic dilation. The patient distribution among these values, relative to age groups at operation, had no statistically significant difference by Fisher exact test.

The distal transverse aortic arch was hypoplastic in 31 (48\%) patients with ratio $<0.9$; in 35 the ratios were $\geq 0.9$. Patient distribution regarding distal transverse aortic arch rate values, relative to age groups at operation, had no statistically significant difference by Fisher exact test.

Correlations. No significant correlation was detected in the ratios at the site of correction (isthmus) with right arm-leg gradient or with Doppler echocardiography.

Patients with recoarctation: Clinical aspects and noninvasive exams. The clinical aspects and results of noninvasive exams in 14 patients with clinical diagnosis of aortic recoarctation are summarized in Table 2 . These 14 patients had the following evolutions: 7 had cardiac catheterization and results are included in Table 3. In 4 patients, the subsequent measures of blood pressure and right arm-leg gradient were lower than that obtained at first clinical examination, so they were followed clinically. A 6-year-old child had diminished right femoral pulse due to previous cardiac catheterization and had elevated right arm-leg gradient; a persistent low left arm-leg gradient was found, but the parents refused MRI. Another patient had persistent fifth aortic arch without indication to further invasive 
TABLE 2. Comparison of clinical aspects with noninvasive methods in patients with high arm-leg gradient

\begin{tabular}{|c|c|c|c|c|c|c|}
\hline \multirow[b]{2}{*}{ Age } & \multirow{2}{*}{$\begin{array}{l}\text { Arm-leg } \\
\text { gradient } \\
(\mathrm{mm} \mathrm{Hg})\end{array}$} & \multirow{2}{*}{$\begin{array}{l}\text { Femoral pulses } \\
\text { (diminished) }\end{array}$} & \multirow{2}{*}{$\begin{array}{c}\text { Arterial } \\
\text { hypertension } \\
\text { (yes/no) }\end{array}$} & \multirow{2}{*}{$\begin{array}{l}\text { Doppler } \\
\text { gradient } \\
\text { (mm Hg) }\end{array}$} & \multicolumn{2}{|c|}{ MRI } \\
\hline & & & & & Lcc-Isa & Isthmus \\
\hline 13 years, 8 months & 45 & Yes & Yes & 39 & 0.56 & 0.61 \\
\hline 9 years, 3 months & 45 & Yes & Yes & 46 & 0.80 & 0.53 \\
\hline 7 years, 11 months & 43 & Yes & - & 37 & 1.50 & - \\
\hline 13 years & 40 & No & Yes & 32 & 0.67 & 1.67 \\
\hline 17 years, 7 months & 30 & No & No & 51 & 0.68 & 0.55 \\
\hline 16 years & 30 & No & Yes & 41 & 1.05 & 0.94 \\
\hline 13 years, 10 months & 30 & No & Yes & 52 & 1.06 & 0.89 \\
\hline 7 years & 30 & No & Yes & 30 & 0.92 & 0.75 \\
\hline 13 years, 8 months & 25 & No & Yes & 27 & 0.83 & 0.61 \\
\hline 2 years, 8 months & 20 & Yes & Yes & 37 & 1.10 & 0.60 \\
\hline 7 years, 9 months & 20 & No & Yes & 40 & 0.81 & 0.73 \\
\hline 6 years, 2 months & 20 & No & No & 24 & - & - \\
\hline 12 years, 8 months & 20 & No & No & 58 & 0.94 & 0.81 \\
\hline 16 years & 20 & No & No & 32 & 0.81 & 0.62 \\
\hline
\end{tabular}

Lcc-Isa, Normalized distal transverse aortic arch; Isthmus, normalized isthmus.

evaluation. One patient dropped out after the noninvasive exams.

Invasive diagnosis. The results of the 11 patients who agreed to catheterization with clinical observation, Doppler gradient, and evolution are summarized in Table 3. One hypertensive patient without right arm-leg gradient but with high Doppler gradient and isthmus stenosis diagnosed by MRI refused catheterization.

\section{Discussion}

\section{The Sample}

This is a select group and not all patients operated during 26 years were included. Most patients were in regular follow-up at our institution. Probably this is the worst spectrum of the disease and consequently the results should not be generalized.

\section{General Clinical Aspects}

The surgical correction of aortic coarctation dramatically changed the natural history of this disease; postoperatively 95 patients $(84 \%)$ were in NYHA class I and 18 were in class II. Blood pressure was within normal levels in 63 patients $(62 \%)$. In one large series, ${ }^{1,4}$ most patients $(87 \%$ 97\%) were in functional class I after correction. Symptoms were more frequent in children operated on at 10 years of age. One explanation for this finding could be the long time the left ventricle was submitted to pressure overload. We chose the right arm-leg pressure as a marker of recoarctation because this is an easily obtainable measurement, relatively easy to implement and to reproduce. But it is important to emphasize that in children younger than 3 years old, it may be difficult to obtain arm-leg blood pressure. Operative techniques such as subclavian flap aortoplasty and end-lateral anastomosis, subclavian artery anomalies, and repeated cardiac catheterization and surgeries cause loss of arterial pulse, and blood pressure measurements became compromised. Furthermore, small children may be stressed during examination. Because of theses aspects we could obtain right arm blood pressure in only $91 \%$ of patients. There was a weak correlation between right arm-leg systolic gradient and continuous wave Doppler gradients. This observation suggests that right systolic arm-leg gradient has a weak predictive value over continuous wave Doppler gradients.

In this study we found no correlation between arm-leg or continuous wave Doppler gradients and residual narrowing degree at the isthmus as measured by MRI. This lack of correlation between variables suggests that gradient reflects not only the degree of narrowing at operation site. The hypoplastic aortic arch may be one factor that intervenes in this relation. Seven of 14 patients with recoarctation had hypoplastic aortic arch confirmed by MRI and 6 patients also confirmed by catheterization. We wonder whether other aspects such as functional and structural alterations in precoarctation vessels and collateral circulation may also intervene. ${ }^{10,11}$ Other authors ${ }^{6,10}$ did not observe correlation with arm-leg gradient at rest and during and after exercise and the degree of narrowing at angiography and MRI. Guenthard and Wyler ${ }^{11}$ found a weak correlation between arm-leg gradient and the degree of residual narrowing site measured by MRI.

\section{Arterial Hypertension}

After surgical correction of aortic coarctation, prevalence of arterial hypertension was reduced significantly to $38 \%$. Some authors ${ }^{12}$ have found higher prevalence of systemic hypertension in children who had end-to-end anastomosis compared with subclavian flap angioplasty. This aspect was 
TABLE 3. Aortic arch gradient at catheterization in 11 patients: clinical and Doppler gradient and management

\begin{tabular}{|c|c|c|c|c|c|c|c|}
\hline $\begin{array}{l}\text { Age at clinical } \\
\text { examination }\end{array}$ & $\begin{array}{l}\text { Catheter gradient } \\
\text { (isthmus) (mm Hg) }\end{array}$ & $\begin{array}{l}\text { Hipoplastic } \\
\text { (aortic arch) }\end{array}$ & $\begin{array}{l}\text { Recoarctation } \\
\text { imaging } \\
\text { (catheter) }\end{array}$ & $\begin{array}{l}\text { Right arm- } \\
\text { leg gradient } \\
\text { (mm Hg) }\end{array}$ & $\begin{array}{l}\text { Doppler } \\
\text { gradient } \\
\text { (mm Hg) }\end{array}$ & Management & Observations \\
\hline 13 years, 10 months & 45 & No & Yes & 30 & 52 & Surgery & $\begin{array}{l}\text { Patch } \\
\quad \text { aortoplasty }\end{array}$ \\
\hline 9 years, 3 months & 45 & Yes & Yes & 45 & 46 & $\begin{array}{l}\text { Balloon } \\
\text { aortoplasty }\end{array}$ & $\begin{array}{l}\text { After balloon } \\
\text { gradient, } 18 \\
\text { mm Hg }\end{array}$ \\
\hline 7 years, 9 months & 35 & Yes & Yes & 20 & 40 & Clinical & $\begin{array}{l}\text { Indicative } \\
\text { balloon } \\
\text { aortoplasty }\end{array}$ \\
\hline 13 years & $34^{*}$ & Yes & No & 40 & 32 & Clinical & - \\
\hline 12 years, 2 months & 26 & No & Yes & 0 & 42 & Surgery & $\begin{array}{l}\text { Patch } \\
\quad \text { aortoplasty }\end{array}$ \\
\hline 17 years, 7 months & $20^{*}$ & Yes & No & 30 & 51 & Clinical & - \\
\hline 26 years, 8 months & $20^{*}$ & Yes & aneurysm & 0 & 43 & Surgery & $\begin{array}{l}\text { Aneurysm } \\
\text { resection/ } \\
\text { tube } \\
\text { between } \\
\text { ascending } \\
\text { descending } \\
\text { aorta }\end{array}$ \\
\hline 13 years, 8 months & $20^{*}$ & Yes & No & 45 & 39 & Surgery & $\begin{array}{l}\text { Subvalvular } \\
\text { aortic } \\
\text { stenosis } \\
\text { resection }\end{array}$ \\
\hline 3 years & 10 & Yes & No & -10 & 55 & Clinical & $\begin{array}{l}\text { Left ventricular } \\
\text { dysfunction }\end{array}$ \\
\hline 12 years, 8 months & 0 & Yes & Yes & 20 & 58 & Clinical & - \\
\hline 11 months & - & - & - & 25 & 16 & Surgery & $\begin{array}{l}\text { Calcified mitral } \\
\text { prosthesis } \\
\text { replacement, } \\
\text { died }\end{array}$ \\
\hline
\end{tabular}

${ }^{*}$ Gradient measured at hypoplastic aortic arch.

not confirmed in the present study. Prevalence of later systemic hypertension in the literature ${ }^{3,13}$ is elevated and reflects some aspects of the studied population, such as age at operation, follow-up period, and the criteria used to define hypertension. At the same time, this diversity hinders the comparison of different studies. Although we could observe that blood pressure decreased abruptly after surgery in all age groups and in some patients it continue to decrease during follow-up, we did not study the continuous behavior of blood pressure along this period. Some authors ${ }^{14}$ observed that prevalence of hypertension diminished abruptly 1 or 2 years after surgery and that blood pressure was normal in the majority of patients 5 to 10 years after correction. On the other hand, after longer periods of arterial blood pressure observation, the proportion of hypertension was higher in every patient age group.

Recently, Seirafi and colleagues ${ }^{15}$ observed that later prevalence of hypertension was low $(5 \%)$ in patients operated before 1 year of age and 6 times more frequent when operated after this age. These results are different from the data obtained in this paper; this can be explained by the short follow-up and the presence of hypoplastic aortic arch. In fact, the long-term behavior of the arterial pressure in children operated for aortic coarctation is not well known, and controlled studies should be performed.

The causes of later arterial hypertension after correction of aortic coarctation are not well known and even patients with normal blood pressure at rest can have hypertension during exercise. ${ }^{14,16}$ Some hypotheses have been suggested to explain the persistence of this problem after a successful correction. Later age at correction of coarctation, ${ }^{14,17}$ operative technique, recoarctation, and hypoplastic transverse aortic arch are also implicated. ${ }^{12,18}$ We suppose that late arterial hypertension in operated coarctation may be the result of a complex interaction of structural arterial and physiologic aspects that persists independently of age and correction of the anomaly, which is not completely understood. 


\section{Recoarctation}

One of the controversies in aortic coarctation is the definition of recoarctation, because of the range of rest gradients accepted to define it and the diagnostic methods used to measure it. ${ }^{19}$ In this paper, noninvasive diagnostic methods could not be conclusive in every patient to diagnose aortic recoarctation. Three noninvasive diagnostic methods were used to obtain greater precision. The number of patients with diagnosis of aortic recoarctation by Doppler echocardiography was elevated (65\%) and incompatible with data obtained by clinical examination and MRI, deserving detailed consideration. In some patients, there was disagreement among the anatomic lesion obtained with imaging diagnostics methods, right arm-leg gradient, Doppler gradient on echocardiogram, and gradient at cardiac catheterization (Table 3). These differences of gradients between Doppler echocardiography and catheterization can be partially explained by high sensitivity of Doppler echocardiography and variable degrees of hypoplasia of transverse aortic arch that may contribute to the gradient measured by Doppler. Furthermore, the instantaneous gradient measured with Doppler obtained by using the simplified Bernoulli equation is not always precise. The exclusion of the proximal velocity overestimates the gradient in mild stenosis. ${ }^{20}$ The proximal velocity in aortic coarctation can be also elevated because of the high cardiac output. ${ }^{21}$ The Bernoulli equation supposes that the pressure distal to stenosis is constant and equal to pressure along the stenotic segment; this is true only with severe stenosis. In mild and moderate stenoses, there is recuperation of velocity after stenosis ${ }^{22}$ that implicates higher gradients in small constrictions. ${ }^{20,23}$

Data in the literature are contradictory about the degree of correlation between instantaneous peak gradient obtained by Doppler echocardiography and measured at catheterization. However, some authors ${ }^{24,25}$ observed that instantaneous peak gradient with Doppler overestimates the peakto-peak gradient measured at catheterization in patients with aortic coarctation. Although continuous Doppler echocardiography is an important method to evaluate aortic coarctation after operation, there are some limitations in cases showing mild obstructions, high cardiac output in patients with hypertension and aortic regurgitation, dilatation of ascending aorta, tortuous vessels, and stenosis in other sites. These considerations may explain the high prevalence of recoarctation found with this method and not previously confirmed by clinical exam or MRI and in some patients with catheterization. In catheterization, gradients $\geq 20 \mathrm{~mm}$ $\mathrm{Hg}$ were obtained in transverse aortic arch in 4 patients and not at the anastomotic site. In these patients, we did not observe the typical recoarctation image at the anastomotic site.

Other authors ${ }^{26}$ showed that in operated aortic coarctation the aortic arch was hypoplastic with greater obstruction at the distal transverse aortic arch. This study demonstrates quantitatively the hypoplastic transverse aortic arch in operated coarctation. Under the denomination of recoarctation there are 2 different anomalies: the stenosis at anastomotic site and the hypoplastic aortic arch that can be isolated or associated. At clinical examination the 2 anomalies cannot be distinguished. Based on this and other data, ${ }^{26,27}$ we infer that true recoarctation is not so frequent and that hypoplastic aortic arch also contributes to postoperative aortic gradient. Some authors ${ }^{28,29}$ have observed growth of the aortic arch after end-to-end anastomosis in infants, but the aortic arch hypoplasia was evident in the patients we studied. These data suggest that hypoplastic aortic arch should be corrected concomitantly with aortic coarctation. We speculate that hypoplastic aortic arch results from incomplete repair of coarctation or lack of growth of distal transverse aortic arch, but this aspect could not be determined by this study.

\section{Conclusions}

None of the noninvasive methods used alone in this study was able to diagnose aortic recoarctation in every case, and they should be used as complementary methods. The right arm-leg gradient obtained during clinical examination is very important to follow these patients. Although Doppler echocardiography is a good imaging method on follow-up, it may overestimate aortic gradient in recoarctation. The hypoplastic aortic arch was highly prevalent and may contribute to persistent postoperative gradient. These data suggest that it should be corrected concomitantly with isthmic coarctation.

We offer our gratitude to Emilia Sakurai, professor of statistics in Federal University of Minas Gerais; to statistician Julienne Moreira Borges who helped with statistical analysis; and to Mrs Patricia Lapertosa for help with the manuscript. We also thank Felicoop for support.

\section{References}

1. Brouwer MHJ, Erasmus ME, Ebels T, Eijgelaar A. Influence of age on late survival, late hypertension, and recoarctation in elective aortic repair. J Thorac Cardiovasc Surg. 1994;108:525-31.

2. Kappetein AP, Zwinderman AH, Bogers AJJC, Rohmer J, Huysmans HA. More than thirty-five years of coarctation repair an unexpected high relapse rate. J Thorac Cardiovasc Surg. 1994;107:87-95.

3. Presbitero P, Demarie D, Villani M, et al. Long-term results (15-30 years) of surgical repair of aortic coarctation. Br Heart J. 1987;57: 462-7.

4. Cohen M, Fuster V, Steele PM, Driscoll D, McGoon DC. Coarctation of the aorta long-term follow-up and prediction of outcome after surgical correction. Circulation. 1989;80:840-5.

5. Bobby JJ, Emami JM, Farmer RDT, Newman CGH. Operative survival and 40 year follow-up of surgical repair of aortic coarctation. $\mathrm{Br}$ Heart J. 1991;65:271-6.

6. Kappetein PA, Guit GL, Bogers AJJC, et al. Noninvasive long-term follow-up after coarctation repair. Ann Thorac Surg. 1993;55:1153-9.

7. Task Force on Blood Pressure Control in Children. Report of second task force on blood pressure control in children. Pediatrics. 1987;79: $1-24$.

8. Clarkson PM, Brandt PT. Aortic diameters in infants and young 
children: normative angiographic data. Pediatr Cardiol. 1985;6:3-6.

9. Clatworthy HW, Sako Y, Chisholm TC, Culmer C, Varco R. Thoracic aortic coarctation: its experimental production in dogs, with special reference to technical methods capable of inducing significant intraluminal stenosis. Surgery. 1950;28:245-73.

10. Hanson E, Eriksson BO, Sörensen SE. Intraarterial blood pressure at rest and during exercise after surgery for coarctation of the aorta. Eur J Cardiol. 1980;11:245-57.

11. Guenthard J, Wyler F. Doppler echocardiography during exercise to predict residual narrowing of the aorta after coarctation resection. Pediatr Cardiol. 1996;17:370-4.

12. Sciolaro C, Copeland J, Cork R, Barkenbush M, Donnerstein R, Goldberg S. Long-term follow-up comparing subclavian flap angioplasty to resection with modified oblique end-to-end anastomosis. Thorac Cardiovasc Surg. 1991;101:1-13.

13. Lerberg DB, Hardesty RL, Siewers RD, Zuberbuhler JR, Bahnson HT. Coarctation of the aorta in infants and children: 25 years of experience. Ann Thorac Surg. 1982;33:159-70.

14. Clarkson PM, Nicholson MR, Barratt-Boyes BG, Neutze JM, Whitlock RM. Results after repair of coarctation of the aorta beyond infancy: a 10 to 20 year follow-up with particular reference to late systemic hypertension. Am J Cardiol. 1983;51:1481-8.

15. Seirafi PA, Warner KG, Geggel RL, Payne DD, Cleveland RJ. Repair of the aorta during infancy minimizes the risk of late hypertension. Ann Thorac Surg. 1998;66:1378-82.

16. Ong CM, Canter CE, Gutierrez FR, Sekarski DR, Goldring DR. Increased stiffness and persistent narrowing of the aorta after successful repair of coarctation of the aorta: relationship to left ventricular mass and blood pressure at rest and with exercise. Am Heart J. 1992;123:1594-600.

17. Bergdahl L, Björk VO, Jonasson R. Surgical correction of coarctation of the aorta. Influence of age on late results. $J$ Thorac Cardiovasc Surg. 1983;85:532-6.
18. Nanton MA, Olley PM. Residual hypertension after coarctectomy in children. Am J Cardiol. 1976;37:769-72.

19. Hanley FL. The various therapeutic approaches to aortic coarctation: is it fair to compare? J Am Coll Cardiol. 1996;27:471-2.

20. Marx GR, Allen HD. Accuracy and pitfalls of Doppler evaluation of the pressure gradient in aortic coarctation. J Am Coll Cardiol. 1986; 7:1379-85.

21. Hatle L, Angelsen B. Doppler ultrasound in cardiology: physical principles and clinical applications. 2nd ed. Philadelphia: Lea \& Febiger; 1985 .

22. Yoganathan AP, Valdes-Cruz LM, Schmidt-Dohna J, et al. Continuous-wave Doppler velocities and gradients across fixed tunnel obstructions: studies in vitro and in vivo. Circulation. 1987;36:657-66.

23. Oshinski JN, Parks JW, Markou CP, et al. Improved measurement of pressure gradients in aortic coarctation by magnetic resonance imaging. J Am Coll Cardiol. 1996;28:1818-28.

24. Chan KC, Dickinson DF, Wharton GA, Gibbs JL. Continuous wave Doppler echocardiography after surgical repair of coarctation of the aorta. Br Heart J. 1992;68:192-4.

25. Wendel H, Teien D, Human DG, Nanton MA. Doppler echocardiographic and morphologic evaluation of patients following operative repair of aortic coarctation. Acta Paediatr. 1992;81:247-52.

26. DeLeon MM, DeLeon SY, Quinones JA, et al. Management of arch hypoplasia after successful coarctation repair. Ann Thorac Surg. 1997; 63:875-80

27. Pinzon JL, Burrows PE, Beson LN, et al. Repair of coarctation of the aorta in children: postoperative morphology. Radiology. 1991;180: 199-203.

28. Siewers RD, Ettedgui J, Pahl E, Tallman T, del Nido PJ. Coarctation and hypoplasia of the aortic arch: will the arch grow? Ann Thorac Surg. 1991;52:608-14.

29. Brouwer MHJ, Cromme-Dijkhuis AH, Ebels T, Eijgelaar A. Growth of the hypoplastic aortic arch after simple coarctation resection and end-to-end anastomosis. J Thorac Cardiovasc Surg. 1992;104:426-33. 